\title{
Ecological depth perception: Ducklings tested together and alone
}

\author{
RICHARD D. WALK and KATHY WALTERS \\ George Washington University, Washington, DC
}

\begin{abstract}
Ducklings were placed either singly or in pairs on a platform at two different heights. Both height and pairing influenced performance: More ducklings descended from the platform at low heights, and more single ducklings descended than paired ducklings. The social factor, pairing, made behavior more cautious and decreased the number of distress calls. A similar trend for pairing to influence performance was shown on the visual cliff. Without its peers, the duckling is a distressed animal. Previous careless behavior by ducklings on the visual cliff may be ascribed to testing the ducklings outside their normal social environment.
\end{abstract}

Many years ago, the senior author asked, "Can the duckling respond adequately to depth?" (Walk, 1962). The query was based on research in which ducklings seemed to be rather careless in the presence of high platforms in comparison with, for example, baby chicks. The preliminary data from that Eastern Psychological Association meeting were subsequently published along with much other research, but the concluding statement on the duckling's depth perception was weak: "The animal discriminates depth but is careless in the presence of depth, too careless to survive in any but a fairly flat terrestrial environment or an aquatic one' (Walk, 1972, p. 21). Walk's (1972) article reported on almost $500 \mathrm{Gi}$ ant White Pekin ducklings tested in a variety of conditions. On the visual cliff, they significantly discriminated visual depth, with $84 \%$ shallow-side choices, whereas the domestic chick approximated $100 \%$ choice of the shallowside (Walk \& Gibson, 1961). The duckling also walked off $46-\mathrm{cm}$ and $1.8-\mathrm{m}$ platforms with little hesitation, although it hesitated more at the higher height. Both the choice behavior and the relative lack of hesitation on the platform seem to indicate some indifference to height, in comparison with other species. On the other hand, pilot results with 18 ducklings presented in the same paper showed longer latencies for ducklings tested in pairs than when alone, and a highly significant correlation $(+.73)$ of latencies when tested with another duckling, which indicates that when one duckling left the platform, the other duckling tended to leave at approximately the same time. Taking account of this, the paper added, "A possible flocking factor may offset the carelessness of the individual animal" (Walk, 1972, p. 21).

The purposes of the present study were to follow up

This research was supported, in part, by NIH Biomedical Research Support Grant 2-S07-RR07019 to George Washington University. Requests for reprints should be sent to Richard D. Walk, Department of Psychology, George Washington University, Washington, DC 20052. the pilot experiment and to investigate more systematically the influence of social factors on the depth discrimination of the duckling. Ducklings were tested alone and in pairs on a threshold apparatus at two different heights and also on the visual cliff. The distress calls of some of the ducklings in the threshold situation were taped and later counted.

\section{METHOD}

\section{Subjects}

The subjects were 48 2-3-day-old ducklings obtained from a commercial hatchery in Long Island, New York. They were secured in batches of 12 and identified by batch letter, A to D.

\section{Apparatus}

Threshold apparatus. The threshold apparatus was a rectangle of $3.8 \times 8.9 \mathrm{~cm}$ lumber. Outside dimensions were $193 \mathrm{~cm}$ high by $58.5 \mathrm{~cm}$ wide; inside dimensions were $185.5 \mathrm{~cm}$ high by $51 \mathrm{~cm}$ wide. It was kept upright by two $8.9 \times 1.9 \times 61 \mathrm{~cm}$ boards perpendicular to the base. The threshold platform was of 6-mm plywood, $51 \mathrm{~cm}$ square, backed for rigidity by a $9 \times 1.9 \times 51 \mathrm{~cm}$ board under it. The two heights, 5 and $46 \mathrm{~cm}$, were made by: (1) $5 \mathrm{~cm}$-resting the platform on the base of the frame; (2) $46 \mathrm{~cm}$-nailing two $9 \times 1.9 \times 15 \mathrm{~cm}$ boards to the inside of the rectangle. The platform was parallel to the floor and attached by C-clamps to the supporting frame by a railing $4.5 \times 1.9 \times 51 \mathrm{~cm}$ at the sides. A vertical backing of $28 \mathrm{~cm}$ high $\times 41 \mathrm{~cm}$ long lumber kept the duckling from seeing the experimenter at its rear and, with the railings, encouraged it to face forward, toward the pattern on the floor.

The pattern on the platform was of $6-\mathrm{mm}$ red and white checks (51 cm square), and the pattern on the floor was of red and white $5-\mathrm{cm}$ checks on plastic and measured $114 \times 168 \mathrm{~cm}$.

Illumination from the overhead fluorescent lighting was approximately $24 \mathrm{fc}$.

Visual cliff. The visual cliff was described in detail elsewhere (Walk, 1966). It is similar to a glass-topped table $1 \mathrm{~m}$ above the floor, with a railing $19 \mathrm{~cm}$ high to keep the subjects on the table, and with a $183 \times 244 \mathrm{~cm}$ surface bisected by a center board $14 \mathrm{~cm}$ wide into two segments of about $183 \mathrm{x}$ $115 \mathrm{~cm}$. A pattern of $1.25-\mathrm{cm}$ red and white checks was directly under one side, the shallow side, and the duckling could see a similar checked surface $1 \mathrm{~m}$ below the glass of the other side, the deep side. Illumination under the center board was equal to illumination on the two sides. Illumination on the visual cliff was approximately $12 \mathrm{fc}$. 


\section{Procedure}

Threshold apparatus. Ducklings were placed either singly or in pairs on the center of the $51-\mathrm{cm}$-square platform and were observed until they had descended to the floor or until $2 \mathrm{~min}$ had elapsed. The experimenter who placed the ducklings could not see them. They were observed by the second experimenter on a TV screen from a TV camera that peered through a hole in a Masonite wall $2.75 \mathrm{~m}$ away. All subjects were tested singly and in pairs at both the 5- and 46-cm heights, a total of four trials for each subject. At each height, half of the ducks were run alone and half were run in pairs; then a new height was used. When the height changed, those run singly at one height were tested in pairs at the second height. A possible order for one animal might be: Trial 1 -alone, $5 \mathrm{~cm}$; Trial 2-paired, $46 \mathrm{~cm}$; Trial 3-paired, $5 \mathrm{~cm}$; Trial 4-alone, $46 \mathrm{~cm}$. Testing was spread over 2 days, two trials per day. Batches $C$ and $D$ had the chirps or calls of the ducklings recorded on a tape recorder. Each experimenter later independently counted the number of calls. The scores used reflect an average of the estimates of the two experimenters.

Visual cliff. The ducklings were placed on the center board, and latency of descent to either the shallow or the deep side was recorded. This testing was much more informal, and only a few ducklings were tested. Ducklings were tested both together and alone.

\section{Calls or Chirps}

The obvious differences in distress calls of the paired and single ducklings prompted preliminary taping of some ducklings of Batch B and full-scale taping of Batches C and D. The "distress calls" were short, high pitched, and regular, and were emitted at the rate of $2-3$ chirps/sec. The loud distress calls shaded off into quieter, almost inaudible chirps, or "contentment" calls. The procedure was to turn the tape recorder on, call out the number or numbers of the ducklings, and then continue taping until 2 min had elapsed or until the duckling(s) had left the platform, an event marked with the word "off" by the experimenter. If one duckling of a pair left before the other, only their time together counted (i.e., when the first duckling left, the experimenter marked "off"). The two problems in estimating chirping were (1) reliability and (2) estimation of chirping rate when time of calling varied from 10-15 sec to 2 min because of varying latencies on the platform.

Reliability. Each experimenter independently counted the calls on the tape. Lone ducklings emit repetitive high-pitched calls and present few difficulties except, perhaps, to the experimenter's sanity: It is a boring, stressful task. Ducklings in pairs emit calls of more variation in intensity, from "contentment" to "distress." We left to experimenter discretion the choice of what to label a "call." One could not ascertain from the tape whether one or two of the paired ducklings were chirping: One simply counted the calls. Because of the range in the amount of chirping (because the ducklings spent different times on the platform), the correlations were high. The correlations of the number of chirps counted by the two experimenters were +.94 for those tested together at $5 \mathrm{~cm}$ and +.95 for those tested together at $46 \mathrm{~cm}$. For lone ducklings, the correlation was +.997 for both $5 \mathrm{~cm}$ and $46 \mathrm{~cm}$. The absolute differences between experimenters were 17.4 chirps for ducklings tested together and 4.6 for those tested alone. Estimating the number of chirps for those in pairs was a more difficult task.

Chirping rate per minute. We converted all calls to estimated number of chirps per minute. As a "standard," we used the number of calls of 12 ducklings that were tested alone and that remained on the platform for the full $2 \mathrm{~min}$, counting the calls in each of four 30-sec time periods. The ducklings chirped most at first and then slowed down a little: $30 \%$ (76 calls) in $0-30 \mathrm{sec}, 25 \%$ (63 calls) in $31-60 \mathrm{sec}, 23 \%$ ( 58 calls) in 61-90 sec, and $22 \%$ (55 calls) in $91-120$ $\mathrm{sec}$, for a total of 252 calls $(\mathrm{SD}=19)$ in $2 \mathrm{~min}(1 \mathrm{st}$ minute $=139$ calls; 2nd minute $=113$ calls). This baseline allowed us to estimate the number of calls per minute, based on the 1st minute, for all ducklings. A duckling that stayed on the platform $25 \mathrm{sec}$ and emitted 68 chirps would be estimated to have emitted $81.6 \mathrm{chirps}$ in $30 \mathrm{sec}, 30 \%$ of the total number of chirps, or 149.6 chirps in the 1st minute. This yields an estimate of $145 \mathrm{chirps} / \mathrm{min}$ for 34 ducklings that left the platform before $120 \mathrm{sec}$ had elapsed, compared with an empirical 139 chirps/min for the baseline group. The correlation of estimated number of chirps per minute and latency on the platform for the 34 ducklings was - 10 , not significantly different from zero. The duckling is a machine for emitting chirps.

\section{RESULTS}

\section{Threshold Platform Behavior}

The results are shown in Table 1. They show that the social variable pairing highly influences performance: $92 \%$ of the ducklings descended from the platform at $5 \mathrm{~cm}$ when alone, but only $25 \%$ of those paired with another duckling; at $46 \mathrm{~cm}, 58 \%$ of the lone ducklings left the platform, but only $6 \%$ of those paired with another duckling. Since each duckling was tested four times, alone and with another duckling at each height, height and pairing can be estimated separately.

Pairing. The appropriate test is that of the change in behavior when tested with another at each height. At the $5-\mathrm{cm}$ height, for example, 34 ducklings that descended when alone remained on the platform when with another duckling, compared with 2 paired ducklings that had stayed on the board when alone that descended when in a pair. Using McNemar's chi-square test on the significance of changes (McNemar, 1955), this is a highly significant change $\left[\chi^{2}(1)=26.69, \mathrm{p}<.001\right]$. Similarly, at $46 \mathrm{~cm}$, more stayed on the platform when paired than when alone $\left[\chi^{2}(1)=21.33, \mathrm{p}<.001\right]$. The overall conclusion is that $75 \%$ descended from the platform when alone, compared with $16 \%$ that descended when tested with another duckling.

Height. Height also influenced the behavior of the ducklings. More descended from the platform at $5 \mathrm{~cm}$ than at $46 \mathrm{~cm}$ when tested alone $\left[\chi^{2}(1)=12.50, \mathrm{p}<\right.$ $.001]$, and more came off the platform at $5 \mathrm{~cm}$ than at 46 $\mathrm{cm}$ when tested in pairs $\left[\chi^{2}(1)=4.92, \mathrm{p}<.05\right]$. Height influenced behavior on the platform, as evidenced by the fact that, overall, $58 \%$ came off the platform at $5 \mathrm{~cm}$

Table 1

Descents From Platform by Ducklings Tested Together and Alone at Each Height

\begin{tabular}{cccccc}
\hline & \multicolumn{4}{c}{ Height } \\
\cline { 2 - 5 } Group & Alone & Paired & & Alone & Paired \\
\cline { 2 - 5 } \cline { 5 - 6 } & 10 & 3 & 6 & 2 \\
A & 11 & 6 & 10 & 0 \\
B & 11 & 1 & 7 & 1 \\
C & 12 & 2 & 5 & 0 \\
D & 44 & 12 & 28 & 3 \\
Total & 42 & 25 & 58 & 6 \\
Percent & 92 & &
\end{tabular}


and $32 \%$ came off at $46 \mathrm{~cm}$. At these moderate heights, pairing was more of an influence on behavior than was height.

Samples. Table 1 shows some differences among samples, although all of the general effects were replicated with each group. A chi-square test showed no significant difference in behavior among the groups for any condition.

\section{Visual Cliff Behavior}

The visual cliff studies were not as formal as the threshold studies in that we tried several different methods of testing the ducklings. Testing of ducklings in pairs on the visual cliff, for example, revealed that the center board was rather narrow for 2 ducklings at a time. We tried placing them in a box from which they could emerge, but they tended to stay in the box. For all this, their behavior clearly revealed that they discriminated depth. Eighteen ducklings were tested alone, and 16 went to the shallow side, 1 went to the deep side, and 1 went over the side to the floor. Fourteen ducklings were tested in pairs; 11 ducklings went to the shallow side and 3 remained on the center board for several minutes. This meant that $100 \%$ of the paired ducklings that came off the center board went to the shallow side, compared with $89 \%$ of the ducklings tested alone.

The tendency for a paired duckling was to discriminate better and to stay with the other duckling rather than make a choice. One presumes that, in the wild, the ducklings would be imprinted on the mother duck and that she would guide the behavior of the ones near her while the others keyed on each other.

The behavior on the visual cliff is in line with the hypothesis that the presence of other ducklings enhances survival rate. To prove this in a meaningful and statistical way would require a great many more ducklings or a better choice situation.

\section{Duckling Calls}

Converting duckling calls into number of calls or chirps per minute permits an analysis of calls by social condition and by height. The ducklings were estimated to emit $144 \mathrm{chirps} / \mathrm{min}(\mathrm{SD}=19.6)$ when alone at $5 \mathrm{~cm}$ and $143 \mathrm{chirps} / \mathrm{min}(\mathrm{SD}=14.9)$ when alone at $46 \mathrm{~cm}$. The pairs emitted 96 chirps $/ \min (\mathrm{SD}=32.2)$ at $5 \mathrm{~cm}$ and 78 chirps/ $\min (\mathrm{SD}=36.3)$ at $46 \mathrm{~cm}$. The paired rate is about $61 \%$ of the calling rate of the single duckling. Depth did not affect chirping, but pairing did. No duckling chirped more in a pair than it did alone, and 24 ducklings were taped twice alone and twice in pairs. For such data, one does not need to compute significance.

Our results can be compared to those of Gaioni, Hoffman, Klein, and DePaulo (1977). They found 150 distress calls/min for single ducklings taken from a larger group. This is a close approximation to our 139-143-chirps/min average for single ducklings, especially when one considers the informality of our technique. Their paired rate for ducklings taken from a group of 12 , the same group size as ours, averaged around 50 calls/min, but the range of their 12 pair samples was 40 to 97 calls/min. Pairs taken from a group of 10 averaged 95 calls/min. Our pairs averaged 96 calls/ min at $5 \mathrm{~cm}$ and $78 \mathrm{calls} / \mathrm{min}$ at $46 \mathrm{~cm}$. Our results overlapped with theirs, and both experiments showed much variability.

The important conclusion, however, is that the duckling chirping data reinforce the depth-discrimination data by showing less distress for the paired ducklings than for those alone.

\section{DISCUSSION}

The experiment shows that the duckling is a social animal and that depth perception for this species can be understood only in the context of its social behaivor. To accuse the duckling of being "too careless to survive in any but a fairly flat terrestrial environment or an aquatic one" (Walk, 1972, p. 21), as the senior author did, is to ignore the importance of its social group.

One can compare the behavior of ducklings with that of gulls, of lambs, and of human infants. Gull environments vary from cliff environments to fairly flat ones (Cullen, 1957; Smith, 1966). The cliff dwellers react strongly to depth-they never fall-whereas flat-environment dwellers are more careless. Those reared in flat country are also reared in colonies, whereas those reared on cliffs are reared alone. A flatlands gull recognizes its own chick among other chicks, whereas a cliff gull mother does not. Whether the more social gull chicks would behave more cautiously in a depth situation when with other chicks is unknown. A reading of Tinbergen's (1953) The Herring Gull's World, a study of ground nesters, fails to reveal flocking behavior. Can gulls be imprinted? Imprinting seems to be related to social influence.

A "social" influence has been found with lambs. Lemon and Patterson (1964) tested "mothered" and "unmothered" lambs on the visual cliff, a contrast of those who remained with the mother and those taken away from her. Mothered lambs discriminated depth about $3-4 \mathrm{~h}$ after birth, whereas unmothered lambs did not discriminate depth until 6-7 $\mathrm{h}$ after birth. The effect, an advantage of only a few hours, was a strong one in that every unmothered twin lagged behind its mothered twin. An unpublished experiment with goats by Lemon (reported in Hahn, 1972) found that kid goats were unaffected by removal from the mother. Goats inhabit a more mountainous environment than do lambs, and lambs are more of a herd animal than are goats. Lambs remain in flocks.

Human infants are responsive to the social factor of "maternal emotional signaling." Sorce, Emde, and Klinnert (1981) employed 12-month-old infants and a moderate visual depth of 12 in. $(30 \mathrm{~cm})$ on the visual cliff. The mothers were positioned on the deep side and instructed to act fearful or to smile confidently. When the mothers pretended to be fearful, none of 17 infants crossed the deep side to them, but 14 of 19 crossed to them when they smiled encouragingly. This is a whopping difference: $100 \%$ remained on the shallow side when the mothers were fearful, but when the mothers smiled with confidence, only $26 \%$ remained there. When a pattern was placed directly under the glass of the deep side, thus eliminating visual depth, the mothers' expressions did not affect the infants' crawling. The infants ignored the mothers' fearful expressions and crossed to them anyway. Only in the ambiguous situation did the infants check the mothers' faces before crawling toward them.

In a representative ecological situation, ducklings are imprinted on the mother and walk behind her or behind another duckling. The behavior of the whole line follows that of the mother, but most of the ducklings are guided by each other. Our experiment shows that the presence of another duckling affects depth discrimination, making the ducklings more cau- 
tious and probably more discriminating, thus enhancing survival rate. The behavior of the duckling, like that of the lamb and the human infant, can be understood only if social factors are taken into account.

\section{REFERENCES}

Cullen, E. (1957). Adaptations in the kittiwake to cliff-nesting. Ibis, 99, 272-302.

Gaioni, S. J., Hoffman, H. S., Klein, S. H., \& DePaulo, P. (1977). Distress calling as a function of group size in newly hatched ducklings. Journal of Experimental Psychology: Animal Behavior Processes, 3, 335-342.

HAHN, E. (1972). On the side of the apes. New York: Arena Books. Lemon, W. B., \& Patterson, G. H. (1964). Depth perception in sheep: Effects of interrupting the mother-neonate bond. Science, 145, 835-836.

McNemar, Q. (1955). Psychological statistics (2nd ed.). New York: Wiley.
Smith, N. G. (1966). Adaptations to cliff-nesting in some Arctic gulls (Larus). Ibis, 108, 68-83.

Sorce, J. F., Emde, R. N., \& Klinnert, M. (1981, April). Maternal emotional signaling: Its effect on the visual cliff behavior of one-year olds. Paper presented at the meeting of the Society for Research in Child Development, Boston, MA.

Tinbergen, N. (1953). The herring gull's world. London: Collins.

W ALK, R. D. (1962, April). Can the duckling respond adequately to depth? Paper presented at the meeting of the Eastern Psychological Association, Atlantic City, NJ.

W ALK, R. D. (1966). The development of depth perception in animals and human infants. Monographs of the Society for Research in Child Development, 31(5, Serial No. 107).

WALK, R. D. (1972). Visual depth preferences of the domestic duckling. Journal of Comparative and Physiological Psychology, 78, 14-21.

Walk, R. D., \& Gibson, E. J. (1961). A comparative and analytical study of visual depth perception. Psychological Monographs, 75(15, Whole No. 519).

(Manuscript received for publication February 21, 1984.) 